\title{
The Stakeholder Perspective on Using Public Polling Displays for Civic Engagement
}

ANONYMOUS, Anonymous,
ANONYMOUS,
ANONYMOUS,
ANONYMOUS,
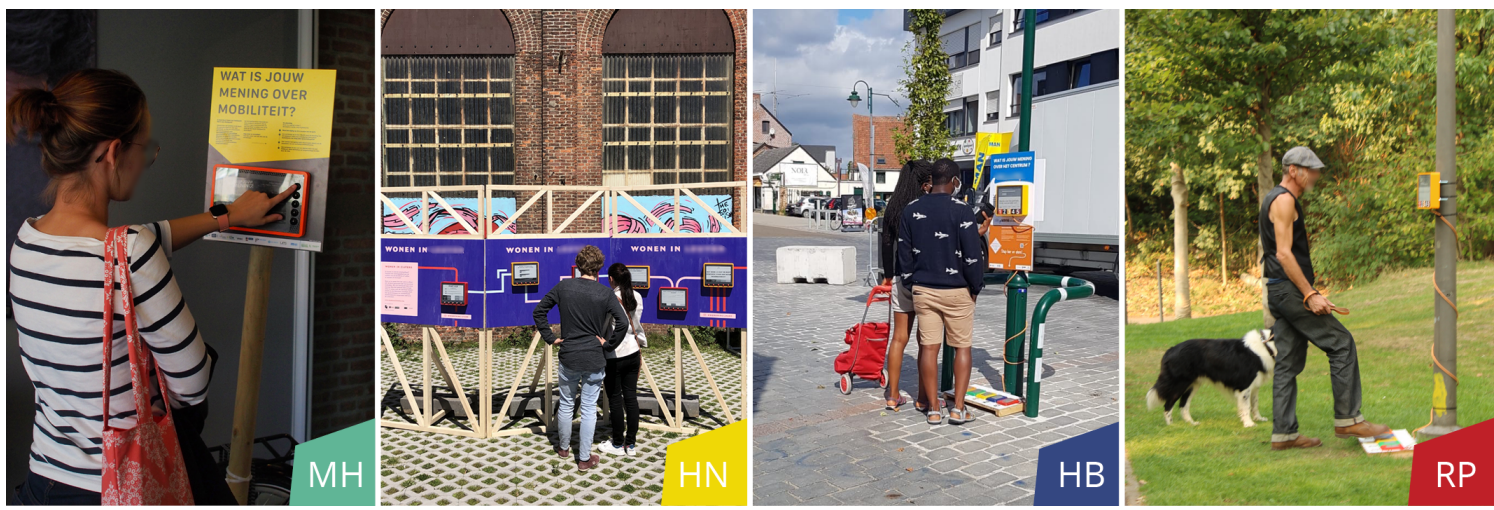

Fig. 1. The four investigated deployments of the same public polling system in different real-world cases. MobiHubs (MH) asked passers-by about their mobility habits and interests. Housing through Numbers (HN) polled local opinions about housing statistics. Habit(at) Breaker (HB) gathered insight into housing preferences. Ring Parks (RP) polled visitors towards the redesign of city parks.

Public polling displays, i.e. interactive interfaces that offer questionnaires in public space, are promised to engage citizens in a dialog with civic stakeholders around local concerns. Although past studies already revealed the core factors that impact their usability, little is known about whether these civic stakeholders actually consider the deployment of public polling displays to be valuable. We therefore interviewed 12 stakeholders who engaged in four different real-world cases, and analyzed all the underlying collaborative activities that ranged from planning the deployments to interpreting the final polling results. We thus report on eight key challenges, among which: designing polls that are responsive, decisive and accessible yet also generate actionable insights, managing the trust of participants as well as the expectations of stakeholders, and facilitating the accurate interpretation of the responses. By understanding the impact of public polling displays from the perspective of stakeholders who actually funded their deployment, we inform its potential evolution towards an opportunistic but also trustworthy civic engagement method.

CCS Concepts: • Applied computing $\rightarrow$ Computing in government; $\bullet$ Human-centered computing $\rightarrow$ Empirical studies in ubiquitous and mobile computing.

Additional Key Words and Phrases: public displays, civic engagement, polling, case study, citizen participation

Permission to make digital or hard copies of all or part of this work for personal or classroom use is granted without fee provided that copies are not made or distributed for profit or commercial advantage and that copies bear this notice and the full citation on the first page. Copyrights for components of this work owned by others than ACM must be honored. Abstracting with credit is permitted. To copy otherwise, or republish, to post on servers or to redistribute to lists, requires prior specific permission and/or a fee. Request permissions from permissions@acm.org.

๑ 2018 Association for Computing Machinery.

Manuscript submitted to ACM 
ACM Reference Format:

Anonymous, Anonymous, Anonymous, and Anonymous. 2018. The Stakeholder Perspective on Using Public Polling Displays for Civic Engagement. In Woodstock '18: ACM Symposium on Neural Gaze Detection, fune 03-05, 2018, Woodstock, NY. ACM, New York, NY, USA, 22 pages. https://doi.org/10.1145/1122445.1122456

\section{INTRODUCTION}

Citizen engagement aims to integrate bottom-up values and preferences into public decision-making, in order to increase the quality of decisions, inform citizens, foster trust in institutions and reduce conflicts [6]. Its basic premise is that all citizens should possess an equal opportunity to participate, and that a representative sample of the population actually takes up this opportunity. However, empirical evidence suggests that a substantial part of citizens do not take up this opportunity [48] because they do not want to invest the required time or effort; experience a lack of local, social or contextual grounding [21,30]; or possess limited rhetorical skills [52]. Public displays, i.e. interactive interfaces that are physically located in public space, have been promised to overcome much of these limitations because they offer completely voluntary and opportunistic forms of interaction through a broadly accepted medium that is direct, easily approachable, safe and informal, yet still credible and trustworthy [29].

As such, public polling displays (PPDs) have been used to offer citizens interactive questionnaires in public space to gather feedback on locally relevant topics $[53,59]$, which can be framed by visualizing dynamic information that is relevant for that questionnaire [5, 12]. Empirical evidence shows that citizens seem to respond in truthful ways [15, 61], even when taking into account eventual faulty entries that are created by situational circumstances such as playing children [23]. Moreover, citizens are more motivated in participating in spatially situated questionnaires versus more conventional ways of polling due to the hyperlocal relevance of the polling questions [24].

Over the last ten years, HCI research has revealed the most fundamental challenges to deploying public displays successfully, including identifying core issues such as display blindness [42], interaction blindness [44] and the perception of irrelevant content [54]. It has also produced a large collection of design guidelines to overcome these challenges and specify the communication of interaction modalities [14], the provision of community values [46] and the handling of technical failures [45]. Additional factors that hinder the effective use of public displays tend to be external to their deployment [41], and can be related to more pragmatic and logistical difficulties [3]. Several recent studies have demonstrated the positive impact of combining public displays with polling functionalities, such as enabling community members to ask questions framed by visualizations of local air quality measurements [12], by offering questionnaires about the perception of neighborhood spaces as an urban game [15], or by distributing voting and feedback visualizations in a community to open up local debates [34].

However, despite this wealth of actionable insights, relatively little is known about whether public polling displays are actually useful for civic stakeholders. Even when most public display studies were based on the 'in-the-wild' research methodology that implies their immersion within ecological valid contexts [51], very few deployments have actually been executed within 'real' civic engagement contexts, i.e. driven by actual civic stakeholder organizations that expect worthwhile and actionable results. While we now have some knowledge regarding the perspective of the practitioners who design or facilitate PPDs [3], and of communities who used relatively simple PPDs [59], the views of the stakeholders who would actually initiate and even fund their use to gather more complex data are still lacking.

This case study thus analyses the impact of four cases in which a single PPD system was deployed from the perspective of ten different stakeholder organizations, five of which also financially supported its real-world deployment. The PPD system is based on a custom technical implementation that combines an e-paper screen, off-the-shelf electronics and 
common battery technologies to facilitate interactive public polling while being fully independent from public energy infrastructure.

First, we describe how we, as the technological and methodological facilitators, guided stakeholders before, during and after the PPD deployments. Then we reflect upon the challenges these stakeholders perceived along this process by analyzing 12 in-depth interviews. This paper thus presents: (1) the impact of four real-world deployments of the same PPD system in different contextual settings; (2) a descriptive model that synthesizes the underlying activities of the facilitators and the stakeholders; and (3) the eight PPD-specific challenges that emerged during the cases.

As civic engagement is transforming from an optional triviality into a highly recommended or even legally-mandated [8] part of any civic decision-making process, this study helps to establish the potential of PPD as a complementary and effective participation method that can claim a place next to face-to-face meetings and workshops [10] or online platforms [65].

\section{RELATED WORK}

A wide range of ICT-based tools for civic engagement have emerged both in research and in practice. While the vast majority of these ICT systems focus on identifying local challenges or collecting citizen feedback and ideas, few aim to trace the actual implementation of these ideas [25]. Yet by mainly developing technological systems that capture citizen opinions, the needs of local institutions - including the mutual trust that needs to be aligned for the trustworthy deployment of these systems - seems still to be lacking $[26,30]$.

\subsection{Civic Engagement Technologies}

Civic engagement systems can be classified according to their initiator, the conscious decision to participate, the level of mediation in that participation, and the limitations towards volume and scale of the collected data [33]. Particularly the latter aspect is often overlooked, as large volumes of open feedback responses can be challenging to process and distill into concrete policy changes for civic authorities [50]. As such, most citizen participation ICT platforms and tools face a wide range of structural and cultural barriers, as governments might lack personnel with technical skill or face resistance to change, and citizens do not have time or may resist technology all-together [39].

In-situ solutions, such as interaction facilitated by personal mobile phones have the ability to overcome some of these barriers because of their opportunistic, voluntary and hyperlocal qualities [24]. While allowing input via mobile phones is becoming increasingly common, their impact is modest as most are limited to crowd-sourced sensing rather than decision-making [17]. In addition, mobile phone polls are considered more pragmatic and opportunistic than conventional municipal websites because they are able to trigger voluntary engagement at a specific location [18], yet while in-situ, citizens prefer to choose from predefined options rather than writing personal responses [55]. Although predefined options produce easier to process data, communicating the resulting insights back to citizens and city authorities as engaging and actionable representations requires close collaborations with data experts [56].

\subsection{Public Polling Displays}

Public displays are traditionally used to present dynamic advertisements, maps or commercial announcements. Yet when being re-appropriated as temporary, interactive "plug-in" interfaces [28], public displays can also form an opportunistic medium to target a very narrowly defined community by being physically located in the actual context of discussion about a local concern. Moreover, PPDs may be deployed by the local community members themselves to raise awareness on local challenges via accessible, low-tech PPD tools, such as paper posters augmented with off-the-shelf electronics 
[63] While interaction with public displays for civic engagement is often facilitated through personal devices such as a mobile phone [13], a PPD can also be controlled via modalities like touch (e.g. [14]), mechanical push-buttons (e.g. [12, 57]), tangibles (e.g. [22]), or bodily gestures (e.g. [29]). Optimizing the quantity and quality of PPD engagements is not straightforward, as it depends on a complex set of spatial [20] and contextual [62] factors such as the physical position, social connotations embedded into the location, as well as the size and relevance of the content [47].

\subsection{Real-World Collaboration}

Facilitating iterative loops of 'action' and 'reflection' in close collaboration with the involved stakeholders are considered key when designing technology for real-world impact [27]. Yet such a 'participatory action design research' [66] approach in conventional ICT systems differs with the application in civic engagement systems in terms of goals, user access and involved stakeholders or decision makers [7]. For instance, because PPDs are typically evaluated through an "in-the-wild" methodology [11], with real-world stakeholders as civic authorities, there can be a discrepancy between the research goals and the expectations of the stakeholders [1]. Therefore, we draw upon a civic engagement level approach commonly used by civic authorities [16] and informed by the 'ladder of participation' [2], i.e. a 'Public Participation Spectrum', that outlines five types of engagement including inform, consult, involve, collaborate, and empower [19].

Tools designed for sustainable community impact should support stakeholders to reflect on the level of civic engagement it enables [16], balance novelty and sustainability and include plans for hand-over to ensure their liveability beyond the facilitation of researchers $[3,4,58]$. Such support can be facilitated through the tools, for instance by inspiring the stakeholders with relevant example questions in the PPD submission tool [57]. However, with assistance, stakeholders may even create responsive questions that follow a more complex polling logic like branching [35].

\section{METHODOLOGY}

\subsection{Public Polling Display System}

Figure 1 depicts the four cases we investigate. Each PPD presented itself as a colorful yet weatherproof enclosure that was attached to various types of urban elements, such as street lights, fences or a temporary and custom-made wooden framework. The system was specifically developed to operate completely independently of pre-existing technical and energy infrastructures while serving two core functionalities: (1) to present polling questions alongside contextually relevant information; and (2) to record the feedback of passers-by upon these questions. The first functionality was initially offered through a monochrome (7.5 inch) e-paper screen, as it required very little energy and was readable in bright environments. As shown in Table 1, this screen was controlled by a Particle Electron micro-controller that was likewise chosen due to its low energy consumption, resulting in a seven-day independent operation with a rechargeable battery. Due to its very slow refresh speed of 6 seconds, the screen was later replaced by a larger ( 9.7 inch) and faster ( 1 second) e-paper screen capable of rendering 16 grayscale values, which had to be driven by a more more power-hungry Raspberry Pi Zero W configuration. Even with an increased battery capacity, this system could only operate independently for approximately two and a half days.

As shown in Figure 2-1 and 2, the second functionality was initially enabled by five mechanical push buttons that were located immediately next to the e-paper screen. To comply with the public health regulations concerning the global COVID-19 pandemic, these buttons were replaced by mechanical foot pedals that were physically connected to the screen with a thick cable in order to signal their affordance (see Figure 2-3). Naturally, each push button or pedal 
corresponded to a discrete multiple choice answer or Likert scale value. While the polling questions were initially uploaded as encoded image files that had to be traversed in a predefined linear fashion, our later PPD version was able to interpret JSON-files that described several potential logic pathways between successive questions. These pathways allowed for more responsive types of polling, as subsequent questions would change based on the previous responses within the same 'session'.

\subsection{Cases}

Each of the cases was embedded in a real civic engagement context, which we describe here from a stakeholder perspective.

Mobility Hubs (MH). Three municipalities (named MH1 to MH3 in Table 2), in collaboration with an expert in participatory design (MH4), wanted to grasp the local perceptions and requirements of Mobility Hubs, i.e. planned local spaces where shared modes of transportation would be centralized and potentially combined with other services (e.g. catering, parcel pickup). Three PPDs were concurrently deployed at each of the planned Mobility Hub locations, which included both rural and suburban locations nearby bus stops, bike racks or car parking lots. This case took place in two deployments, as the multiple-choice responses of the first iteration (e.g. "Which transport did you use to come here?") informed a hands-on participatory workshop, of which the results were shown alongside Likert-scale questions during the second deployment (e.g. "A Mobility Hub in each nearby center would encourage me to use my car less frequently.").

Housing through Numbers (HN). An NGO advocating architectural and urban design values (named HN1 in Table 2) wished to spark a more nuanced public debate on the complexities of the current housing market in a mid-sized city (HN2). As such, four infographical narratives were designed based on a recent statistical report on the city's housing situation, by visualizing trends and notable outliers along with other relevant metrics, such as those from other nearby municipalities or from different demographic groups. These data narratives were presented as a single, temporary installation by way of six co-located PPDs. After participants chose a preferred data narrative on the first PPD, each

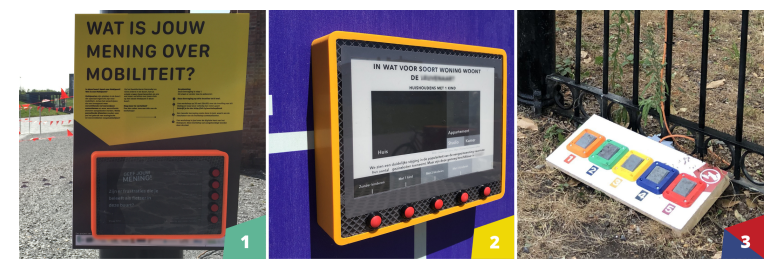

Fig. 2. The PPD system deployed throughout the four cases evolved: from a (1) 7.5" monochrome displays in MH, to (2) 9.7 " grayscale displays in $\mathrm{HN}, \mathrm{HB}$ and RP, and (3) the added foot pedal interaction modality in $\mathrm{HB}$ and RP.

\begin{tabular}{|c|c|c|c|c|c|c|c|c|c|c|}
\hline Case Id & Case & Theme & $\begin{array}{l}\text { Question } \\
\text { Flow }\end{array}$ & $\begin{array}{c}\text { Question } \\
\text { Asked }\end{array}$ & Interaction & Technology & Location & Setup & Signage & Duration \\
\hline MH & MobiHubs & Mobility & Linear & $12 \& 13$ & Push Buttons & $\begin{array}{l}7,5^{\prime \prime} \text { monochrome } \\
\text { Electron }\end{array}$ & $\begin{array}{c}\text { Rural, } \\
\text { Suburban }\end{array}$ & $\begin{array}{c}3 \text { displays } \\
\text { per municipalities }\end{array}$ & $\begin{array}{c}\text { Call to action on } \\
\text { information panel }\end{array}$ & 42 days \\
\hline HN & $\begin{array}{c}\text { Housing } \\
\text { through } \\
\text { Numbers }\end{array}$ & Housing & Linear & 21 & Push Buttons & $\begin{array}{l}9,7 " \text { greyscale } \\
\text { RasPi }\end{array}$ & Urban & $\begin{array}{l}6 \text { display installation } \\
\text { at } 4 \text { locations in one } \\
\text { municipality }\end{array}$ & $\begin{array}{c}\text { Large scale } \\
\text { wooden installation } \\
\text { and visual guide }\end{array}$ & 33 days \\
\hline HB & $\begin{array}{c}\text { Habit(at) } \\
\text { Breaker }\end{array}$ & Liveability & Responsive & 37 & Foot Pedals & $\begin{array}{l}9,7^{\prime \prime} \text { greyscale } \\
\text { RasPi }\end{array}$ & Suburban & $\begin{array}{c}3 \text { displays } \\
\text { over distributed locations }\end{array}$ & $\begin{array}{l}\text { Call to action on } \\
\text { information panel }\end{array}$ & 24 days \\
\hline $\mathbf{R P}$ & $\begin{array}{c}\text { Ring } \\
\text { Parks }\end{array}$ & Placemaking & Responsive & 13 & Foot Pedals & $\begin{array}{l}9,7^{\prime \prime} \text { greyscale } \\
\text { RasPi }\end{array}$ & Metropolitan & $\begin{array}{c}2 \text { displays } \\
\text { over distributed locations }\end{array}$ & $\begin{array}{c}\text { No additional } \\
\text { signage }\end{array}$ & 14 days \\
\hline
\end{tabular}

Table 1. Overview of the contextual factors surrounding the four cases. The amount of questions are maximum values, as they depend on previous responses in the responsive polls of $\mathrm{HB}$ and RP. 
other PPD became updated to present a provocative question that captured existing preconceptions (e.g. "Which is the most expensive city to live in?") or potential solutions (e.g. "What is the most important factor guiding your housing choices?"). The whole installation was deployed at four different locations throughout the city for a total of five weeks, and additionally during three one-day events at two separate locations.

Habit(at) Breaker (HB). A mid-sized municipality (named HB1 in Table 2) and a regional government body (HB2) wanted to continue involving local citizens to reflect upon near-future visions of greenery, recreation and suburban centers in a way that overcame the physical meeting restrictions during the COVID-19 pandemic. This poll contained multiple responsive questions, so that certain responses (e.g. "I mainly come here to shop.") were followed by appropriate follow-up questions (e.g. "What type of shopping in particular?"). The PPDs were deployed at three locations with a direct connection to the three themes, i.e. a hiking route (greenery), a public swimming pool (recreation) and main shopping street (suburban center).

Ring Parks (RP). An urban planning office (named RP1 in Table 2) and public broadcaster (RP2) wanted to collect local opinions regarding two city parks that would be redeveloped to ameliorate the effects of a large and politicallycharged infrastructural intervention. One PPD was deployed in each of the parks in close proximity to the planned intervention. Their polling questions offered multiple-choice responses regarding current practices (e.g. "How often do you come here?") and future ideas ("Would a playset be a good addition here?") for the parks, which were structured in a responsive way (e.g. "What should be included in the park above all?", and if "Recreation" was chosen: "What type of recreation?").

\subsection{Data Collection}

First, we analyzed the polling responses that were logged by the PPDs. We further executed various on-site observations (totaling approx. 63 hours across all cases), had occasional spontaneous interviews with partaking citizens, which we will refer to as 'participants' (totaling 85 interviews across all cases, each between 2 and 10 minutes). The first two authors kept a close record of the intermittent meetings and communications with stakeholders in their research diaries.

\begin{tabular}{|c|c|c|c|c|c|c|}
\hline \multirow[b]{2}{*}{ Interview id } & \multirow[b]{2}{*}{ Expertise } & \multirow[b]{2}{*}{ Organization type } & \multicolumn{4}{|c|}{ Skills } \\
\hline & & & Technical & Citizen Engagement & Polling & Thematic \\
\hline MH1 & Mobility & Municipality & 4 & 2 & 0 & 4 \\
\hline MH2 & Mobility & Municipality & 2 & 4 & 3 & 5 \\
\hline MH3 & Mobility & Municipality & 3 & 3 & 2 & 3 \\
\hline MH4 & Participation & Researchers & 4 & 5 & 5 & 4 \\
\hline HN1 & Housing & NGO & 4 & 4 & 2 & 4 \\
\hline $\mathrm{HN} 2$ & Urban planning & Municipality & 3 & 4 & 2 & 4 \\
\hline HB1 & Urban planning & Municipality & 2 & 4 & 2.5 & 5 \\
\hline HB2 & Urban planning & Regional government & 4 & 3 & 5 & 4.5 \\
\hline \multirow{2}{*}{ RP1A, RP1B } & \multirow{2}{*}{$\begin{array}{l}\text { Urban planning } \\
\text { and participation }\end{array}$} & \multirow{2}{*}{ Commercial agency } & RP1A 3.5 & RP1A 4.5 & RP1A 3 & RP1A 4 \\
\hline & & & RP1B 3 & $\mathrm{RP} 1 \mathrm{~B} 4$ & $\mathrm{RP} 1 \mathrm{~B} 2$ & RP1B 5 \\
\hline \multirow{2}{*}{ RP2A, RP2B } & \multirow{2}{*}{ Co-Creation } & \multirow{2}{*}{ Public Broadcaster } & RP2A 4 & RP2A 4 & $\mathrm{RP} 2 \mathrm{~A} 4$ & RP2A 3 \\
\hline & & & RP2B 4 & RP2B 2.5 & RP2B 4 & RP2B 1.5 \\
\hline & & Averages & 3,38 & 3,67 & 2,86 & 3,92 \\
\hline
\end{tabular}

Table 2. Overview of the interviewed stakeholders, including their interview id, stakeholder type, expertise, anonymized affiliation, and self-reported thematic experience regarding the addressed topic and technical, citizen engagement and polling skills. 
After all deployments were finished, we interviewed 12 individuals from the 10 different civic stakeholder organizations, some of which occurred concurrently in pairs (i.e. RP1 and RP2). While on average all stakeholders felt confident in terms of engaging citizens in participatory processes and the themes that were subject of the polls, they were less familiar with polling as a method of civic engagement. The interviews for MH, HN and HB were conducted by the first author in the local language, while interviews about RP were conducted in English by the second author. Selected quotes of $\mathrm{MH}, \mathrm{HN}$ and $\mathrm{HB}$ were subsequently translated to English to support analysis. The interview duration ranged from 35 minutes (MH2, HN2) to 1 hour and 30 minutes. The list of interview questions and the code book are made available as part of the supplemental materials ${ }^{1}$.

Using 26 coding themes deduced from the interview questions, the first two authors independently coded the interviews they had conducted, leading to 512 selected unique quotes (avg. 51 per interview). The third author, who was not involved in the interviews, familiarised themselves with the data and reviewed all thematic codings. This resulted in 2 changes and 15 additions that emphasized our facilitating role and the challenges faced by stakeholders The research diary of each case was formulated into a thick description [49] of the activities that were undertaken, which were then synthesized into four successive phases. The activities inside the phases were iteratively defined and named in a collaborative drawing and mapping process between all four authors.

\section{PUBLIC POLLING DISPLAY COLLABORATION PROCESS}

During each case, we presented and positioned ourselves as 'facilitators', i.e. experts who were able to organize all practical matters in both conceptual as technical terms. Concurrently, as academic researchers, we focused on our interactions with the primary stakeholders. Yet we were also aware of the influence from secondary stakeholders, i.e. professionals who were approached by the primary stakeholders - often within their own organizations - to fill a specific knowledge gap. Although they were occasionally mentioned by the primary stakeholders during the process and the interviews, we had no direct contact with these secondary stakeholders.

The PPD process model shown in Figure 3 synthesizes the activities by these stakeholders, ourselves and participants before, during and after the actual installments of the PPDs. Specific challenges during the collaboration process between the facilitators and stakeholders are mapped along the phases, and discussed in the relevant passages of section 6. Stakeholder Perspective.

The Planning phase consisted of 'Formation' meetings that introduced the PPD features on one side, and the civic engagement goals on the other. Then, the content, location and timing became 'Orchestrated' through an iterative process of local site visits and content revisions (2 to 7 rounds per case) and informed by timing requirements. Content was developed based on back-and-forth discussions via email or during workshop-like settings (up to 3 per case) that contained editorial reviews and cognitive walkthroughs [36] in which the logic and flow of the questions was fine-tuned.

The Deployment phase comprised 'Field Work' activities to install and maintain the PDDs on-site. During the deployment, the PPDs recorded polling responses that were communicated to the stakeholders in intermediate reports using simple data visualizations. Often these results were used together with participant feedback to 'Steer' the deployment by promoting the presence of the PPDs to the local population.

During the Interpretation phase, we 'Processed' and then reported the final polling responses to the stakeholders by sharing raw data and visualizations. Some civic stakeholders requested additional interpretations, which typically ranged from statistical comparisons between individual PPDs (RP) to more qualitative interpretations of the collected

${ }^{1}$ http://tiny.cc/civicpd 


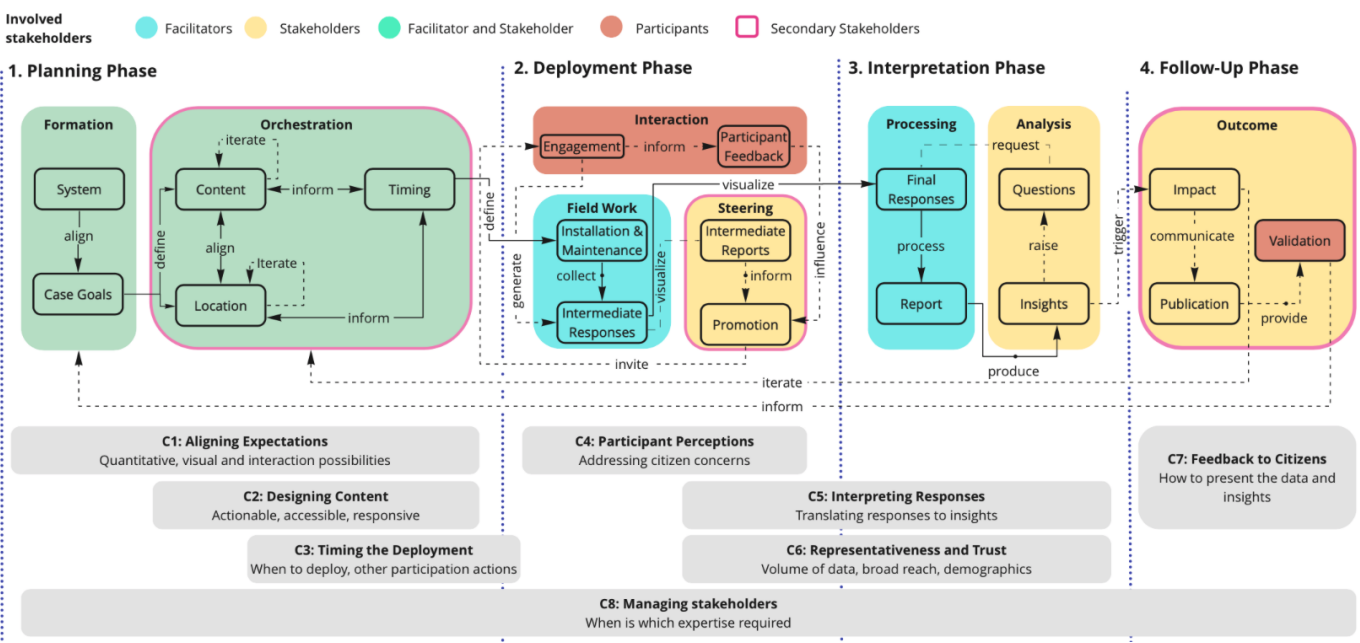

Fig. 3. The activities underlying each PPD collaboration were organized in four successive phases: (1) planning, (2) deployment, (3) interpretation and (4) follow-up. Each phase contains a set of specific activities (e.g. 'Preparation' or 'Orchestration' during in the Planning phase) that comprises of multiple facets (e.g. 'System' and 'Case Goals'), interconnected through lines that represent actions (e.g. 'align'). Solid lines depict activities that occurred during all cases, while dashed lines were more circumstantial. The background color of the activities signifies the involvement of different stakeholders according to the legend on top, while a colored border is used to indicate the known influence of secondary stakeholders. Below the model, we mapped out the 9 key challenges that impacted the PPD collaboration process.

data (MH). Stakeholders then used this information during their in-house 'Analysis' to produce their own insights. Occasionally, stakeholders requested additional data processing, such as to group the PPD responses in different locations to the same question (HB, $\mathrm{HN}$ ) or to visualize correlations between specific responses (HB).

The final Follow-up phase captures the 'Impact' from the actions that stakeholders took (or refrained to take) based upon their insights from the Interpretation phase. In one case (MH), an additional PPD deployment iteration enabled citizens to react upon findings informed by a previous iteration. Other stakeholders (HN, HB) communicated their insights in publications in order to provide transparent feedback and validation to the citizens who had participated.

\section{PARTICIPANT PERSPECTIVE}

We believe it is necessary to also present the quantitative impact of the PPDs in order to contextualize the actual experience of the stakeholders. We thus first provide a concise overview of the logged data, as well as the most salient insights from our observations and on-site participant interviews.

Table 3 presents an overview of the digital logs. In HB and RP, participant engagement is grouped as 'sessions', i.e. clusters of sequential votes that were cast before the interface automatically returned to its starting screen (60 seconds), and 'interactions', which correspond to the number of pressed foot pedals. As the session counter was not yet implemented, we report instead on the amount of answered questions for MH and approximate the number of unique participants through the number of narratives that were started on the first display of the HN installation.

Although we cannot generalize across the different cases, we notice that in general a PPD can attract from 39 to 67 unique 'sessions' per day, with typical peaks between the early afternoon (from 2PM) and early evening (to 7PM), due to school and office closing hours. Differences between concurrent PPDs showing similar content can be explained by 
Case Engagement per day

Total

Sessions Interactions Responses

Locations Municipality $1 \square$ Municipality $2 \square$ Municipality 3

MH

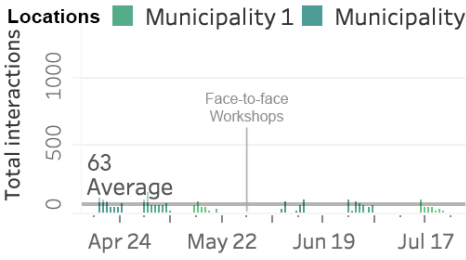

HN

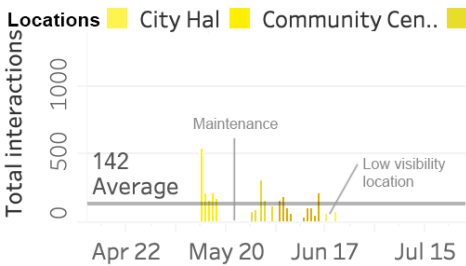

Apr 22 May 20 Jun 17 Jul 15

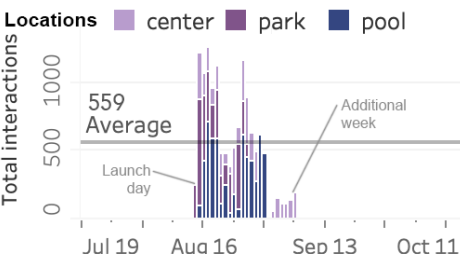

Jul 19 Aug 16 Sep 13 Oct 11

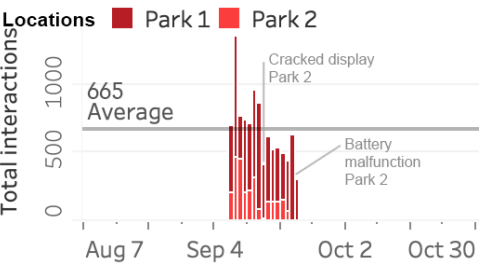

Housing Develo.. — Library

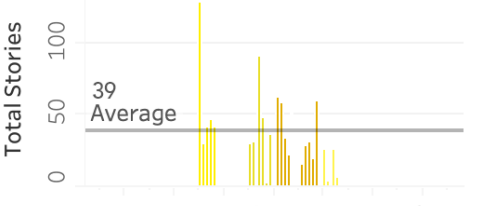

112

N/A

2902

Apr 22 May20 Jun $17 \quad$ Jul 15

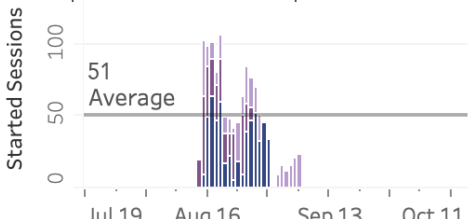

question

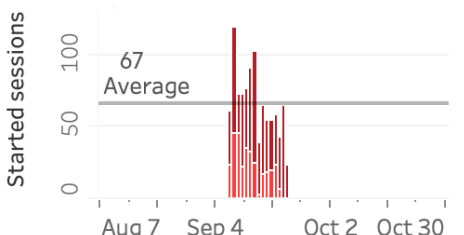

Avg. 35 /

question

Table 3. Overview of the logged data of the four cases. The daily engagement is depicted in total interactions per day. Where possible, we approximate the number of individual participants based on different indicators: in $\mathrm{HN}$ the number of narratives that were started; in HB and RP the number of 'sessions' that were started, i.e. clusters of responses that were separated by a certain idle time (60s). Note that the volume of questions asked differs between cases and is affected by the responsive question flows. Along with the foot pedal interaction in HB and RP (see Table 1), these difference likely impacted engagement rates, and the duration of interaction depicted in the average number of responses per question.

the amount or diversity of passers-by, as a location such as the swimming pool (HB) is much more frequented than one of the local parks visited by people who did not master the local language (RP).

The foot pedal modality did not negatively affect PPD performance. In contrast, we noticed how their playful nature drew the attention of passers-by by functioning as a "curiosity object" [32], "... they are easy, very good that you don't need to use your hands." (participant, HB). The foot pedals also afforded social engagement, as some couples divided controlling the pedals among themselves, or parents directed their children to cast their votes (see Figure 4). Because this modality required a constant shift of attention between the display and the pedals, we observed several instances during which participants voted twice before noticing the (1s) latency between a physical vote and its content update. 
As some older participants tended to use surrounding urban infrastructure for physical support, the accessibility of the foot pedals seemed not universal, which could harm the inclusive quality of the polling.

Many participants were enthusiastic ("I think it's a good initiative"-participant, HB), and felt encouraged by the possibility to "... vote at the end and give my opinion." (participant, HN). Some were positively surprised by the honest and critical look at a serious issue ("This can't be from the city, it's much too critical, it really shows the problems."-participant, $\mathrm{HN}$ ). Participants were often first drawn-in by the novelty of the PPDs, and became motivated to vote as they found ".. it important that the government checks design decisions with citizens" (participant-RP). Participants validated our PPDs as a more accessible form of civic engagement because "...this you can do yourself whenever you want, otherwise its on a specific day, in the cultural center, for a whole evening" (participant, HB). Others expressed skepticism towards the value of their vote ("Hope the municipality does something with this!"-participant, HB), or did not believe "...that the municipality will act upon the gathered results" (participant, RP), as the parks were already changed previously without any citizen involvement.
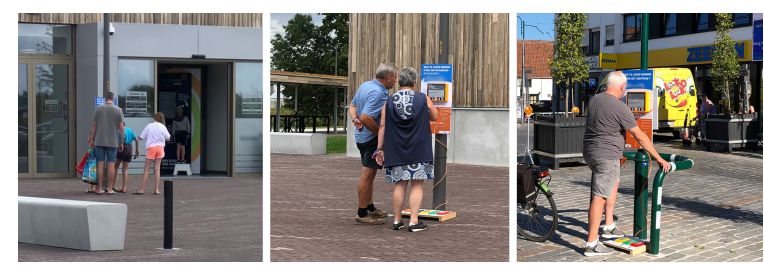

Fig. 4. The playfulness of the foot pedal modality was observed to draw-in curious passers-by. While it enabled parents and their children (left) or couples to collaboratively interact (center), it yet also caused some participants to look for physical support (right).

\section{STAKEHOLDER PERSPECTIVE}

\subsection{Planning}

6.1.1 Formation. Stakeholders valued the location-specific nature of the PPDs to "...capture people who are using the space today" (MH1). The stakeholder goals in MH, HB and RP in particular focused on consulting people who used specific physical locations, "...the local people are actually the 'connaisseurs' of this location."(RP1A). All stakeholders aimed to reach a diverse audience and perceived our PPD approach to be accessible and opportunistic as it targeted a difficult to reach sample of citizens ("It goes] beyond people who have time and technical or verbal skills"-MH4) over a longer period of time ("It is always there, and then you encounter it"-HB2). As such, they believed that PPD casts a wider participation net ("Two working people with children will be difficult to draw to a workshop, compared to providing an [interaction] point in the neighborhood and you decide when you go."-MH3).

The straightforward aesthetic appearance of the PPD with its "...bright colors in public space are something that's playful."(RP2B), conveyed a neutral impression ("I don't think anyone cares or sees them as a bad thing; they look nice."RP1A) and might diminish the potential for vandalism ("It did what it was supposed to do without - and this is good any fuss."-MH1). Across the 113 days and nights of deployment, we recorded only one instance of vandalism in the form of a cracked display (RP, marked in Table 3). The PPDs were valued as a unique 'phygital' [43] approach that combines the digital and physical to continue civic engagement during the COVID-19 pandemic ("We had a huge setback on physical meetings, [this was] a very good instrument to still let people actively participate."-RP1A), and the foot pedals were believed to "...look really fun to do."(HB2). 
6.1.2 Aligning Expectations. Stakeholders who were more familiar with qualitative methods like workshops noted the absence of open questions ("You miss some valuable information..."-RP2B) and the collection of personal anecdotes that could inspire the next steps ("This is where you get your inspiration from."-RP1B). However, qualitative approaches were said to be more "...expensive and labor intensive" (MH1). Figure 3 shows that stakeholders were not involved in 'Field Work' during the deployment phase. Once stakeholders realized how PPDs sparked discussions among participants in their immediate vicinity, they felt disappointed these could not be captured ("I think that the discussions between people around the installation are hard to monitor [without physical presence], but are also interesting actually."-HN2).

Most stakeholders were well-aware of the visualization ("Of course your display has a limited size, requiring you to be selective in the information you ask or show."-MH1) and interaction limitations ("Five button, clicking through."-HB2) of the PPDs. Yet even after demonstrating content from previous cases, at least one stakeholder (HN1) still expected functionalities that resembled that of a standard public display ("It was unclear what the end result would be in a visual sense."-HN1). Some felt limited by the discrete interaction modality, as only one out of five possible responses could be logged, so that "...people [who] wanted to select two options, that was not possible." (HB2). Others based their expectations on experiences of commercial polling systems to instantly access intermediate results in order to "... follow how many questions have already been answered." (MH1).

Challenge 1: Aligning Expectations. The novel features offered by PPDs as a civic engagement medium can be misaligned to the expectations from stakeholders, which are often based upon their experience with already existing participation tools. The technological limitation to solely capture quantitative data forms a core adjustment to the civic engagement experience, as well as the constrained visualization and interaction features.

6.1.3 Decisive Questions. Stakeholders aimed for direct questions that provide outspoken and actionable responses ("For example, there is a bike here, would you use it?"-MH1) rather than the implemented probing questions (e.g. "Which factors prevent you from using alternative transportation modes?" in $\mathrm{MH}$ ). Consequently, some disliked multiple-choice options like "prefer not to say" or "other" as it enables "... the participants not to make a choice." (HB1). Vice versa, presenting questions that suggested direct votes on an actual outcome were considered risky, as it could provoke misuse ("You cannot build your policy solely on these [results]."-HB2).

6.1.4 Informative Content. It was believed that a PPD poll should limit the amount of questions as "...few people would have remained engaged to the end" (HB2, 37 questions), and it was uncertain "... where you reach the limit with people, [...] that they still answer" (RP1A, 13 questions). Maintaining an overview of the multitude and order of polling questions was considered challenging ("If you have a [branching] poll that's way bigger, it's very complicated."-RP2A) and something that required a particular skill that we as facilitators were expected to accommodate ("You are building a question tree, and to keep track of the branches of that tree was [the facilitators'] strength."-HB1). Several stakeholders (3, N=10 interviews) requested a more grounded basis for how the polling question were worded and structured: "...the purpose of that specific question, what do you get out of it?" (MH3) and wanted the facilitators to explain "... what the theoretical underpinnings are"(MH1). In contrast, when the stakeholders designed polls by themselves, they "...do it based on gut feeling."(MH1).

Stakeholders believed a PPD should present contextual information to the participants before polling: e.g. "You show traffic counts, road categorization etc. [...] so people can understand why you want to make changes."(MH2), which yet had to be balanced with framing the topic in engaging and accessible ways ("If you talk about [complex topics] you need a lot of words, but you also have to keep attention spans in mind."-MH4). The accessibility of a PPD could be significantly 
improved by offering multiple languages or visual instructions "...particularly if you look at [City] where not everyone has mastered the language."(MH4).

Challenge 2: Designing Content. The design of polling questions is challenging and beyond the ability of stakeholders. The number of questions has to be balanced with the opportunistic quality of the system to allow participants to answer a complete poll quickly, while also providing relevant contextual information alongside. In addition, questions need to provide direct and actionable responses without insinuating conclusive decision making power. Finally, stakeholders struggle with complex and responsive polling structures, yet wish to understand the reasoning behind the specifically chosen wording and architecture.

6.1.5 Urgency. The deployments were mainly driven by strict deadlines ("There was little time. We needed to install those displays as quickly as possible, same for composing the poll."-MH4), as the stakeholders wanted to use the polling results in their decision making ("We had made a lot changes and realized we had to start monitoring how people perceived them!"-HB1). The polling questions reflected timely ( "The results show that people want green and safe streets, yet everyone is always yelling when parking disappears. That's the discrepancy we now want to put forward."-HB1) and even politically charged concerns ("You feel there are, let's say, societal conflicts going on."-RP1A), insofar that some deployments had to be postponed due to expected political frictions ("We needed to put it on hold for the upcoming elections."-HN1). This relevance increased the PPDs' usefulness for participants, but also assured a smooth administrative workflow in regards to getting official permits or hard-to-get data ("It is our role to give the geo-based data [...] and the locations to make these kinds of experiments possible."-RP1A ).

\subsection{Deployment Phase}

6.2.1 Promoting. Stakeholders had difficulty in estimating if the volume of interim responses was satisfactory ("From your experience, was it used often or rarely?"-HN1), in order to determine the need for additional promotional actions, "...to launch another call [to participate], or consider moving the displays."(HB2). Some believed that the deployments should be aligned with other events to involve additional participant groups ("I believe there was an open day at the school. We could have better connected to events at the location."-MH4).

In two cases (MH, HB), the PPDs' signage (see Figure 1) was used to frame the deployment in relation to other concrete actions, i.e. the face-to-face workshops in each MH municipality, or an online poll that offered identical questions in HB. Although this signage was appreciated because it "...invite additional people in"(MH3), only 57 participants responded to the online poll in HB during the same period of 3 weeks in comparison to 510 "sessions" of the PPD in which participants answered all location specific questions.

Challenge 3: Timing the Deployment. Organizing the practical deployment of a PPD is challenging, particularly when it forms part of a more encompassing civic engagement initiative that exists because of a certain sociopolitical context. At the same time, this relevance is able to generate an urgency that attracts the attention of participants and ensures fluid official approvals and permits as secondary stakeholders are already aligned.

6.2.2 Interim Participant Feedback. In multiple interviews (5, $\mathrm{N}=10)$ stakeholders did not recall any spontaneous feedback during or after the deployments, yet in some cases (M, HB) participants contacted them on social media or in person. Interim participant feedback can be mixed according to the other stakeholders, and focus on concerns about usability ("... the [slow updating] speed of the displays."-MH3), aesthetics ("[They said] it looks very simple and it works 
very well."-RP1A) or the methodological novelty ("A council member said that they were asked about and complimented on the novel approach."-HB2). In HB, some citizens used Facebook to express concerns about the trustworthiness of a PPD due to its anonymous character and playful appearance, questioning "... how representative the responses would be because there are children playing with the pedals."(HB1). Other citizens suggested a concurrent online alternative to solve accessibility concerns, as they questioned "... what to do if they could not physically go to the locations."(HB1).

Challenge 4: Participant Perceptions. Participants raise critical reflections particularly when they expect that the polling results might indeed impact official decision making or have implications beyond the immediate deployment location. While such concerns were relatively rare, it should be noted that no easily accessible (or anonymous) communication channel existed for citizens to express these sentiments as stakeholders did not foresee them and thus did not preemptively address them in their communication.

\subsection{Interpretation Phase}

6.3.1 Interpreting Responses. Depending on the their data interpretation skills, stakeholders had varying levels of success independently generating useful insights based on the visualizations we provided to represent the intermediate or final responses. While all stakeholders found it useful to receive intermediate updates to estimate the need for promotion, they did not possess sufficient data literacy skills to feel confident in drawing conclusions from the final results ("We don't have data people to work with. It could be that we misinterpret the data."-RP1A or "I sometimes have to pass on the data, we are not as used to handling all those numbers."-HB1). Stakeholders who operated in small teams (e.g. in suburban city) did not have the liberty to spend time on analyzing this data: "I don't have time to start analyzing all of that myself." (MH2). Seeking help externally was considered insufficient, as stakeholders felt that the generation of meaningful or actionable insights required an appreciation of the local context ("You need a piece of context, otherwise you are merely looking at numbers."-HB1). This should therefore be approached as a collaborative process "...that we do also together with you, [the facilitators]."(RP1A). In contrast, for very targeted deployments with only a limited number of narrowly-defined questions, stakeholders believed that "...it would be possible for a municipality to process [the results] internally."(MH3).

Challenge 5: Interpreting Responses. The meaningful interpretation of the polling responses is challenging, because the stakeholders have limited skills or resources to analyze them, and the potential inclusion of external support lacks the required contextual knowledge. Figure 3 illustrates the emblematic separation of facilitators and stakeholders in this phase, as the activities of those who posses local knowledge and those who are experienced in handling data do not overlap.

6.3.2 Stakeholder Insights. Some polling results were able to change strong preconceptions of the stakeholders: "I find that very remarkable. I expected no one to pick that."-HN1 and "Even more notable, a majority says building and living at smaller scale is the solution. Absolutely unexpected."-HN1. In HB, the notion that more attention should be spent on the safety of cyclists and pedestrians was considered insightful ("I'm actually proud that [our inhabitants] put cyclist and pedestrian safety and greenery at number one."-HB1). Other polling results confirmed prior understandings, such as how participants approved recent mobility changes ("I think this clearly demonstrates that there is absolutely no demand to return to two-way traffic. The need for parking is much less pronounced than some would have believed."-HB2). In MH, the polling results emphasized the potential of the MobiHub concept (e.g. 28/40 responses in one municipality agreed that 
local discounts would motivate to use eco-friendly mobility), and revealed unexpected similarities between rural and urban areas: "Actually on municipal level, there are in fact overlaps in responses with bigger cities, so there is some interest in shared mobility on our scale too."-MH3. In RP, the polling results confirmed previous knowledge, such as the local desire for a city 'forest', and unveiled new insights, including a need for more safety around the bridge that connects both parks ("With this number, it is actually worthwhile to have a separate question dedicated to this."-RP1A).

6.3.3 Representativeness and Trust. After experiencing the PPD process, stakeholders felt convinced that PPD "...can be an objective way for many citizens to give an answer"-(MH1). In some interviews $(4, \mathrm{~N}=10)$, stakeholders considered the insights from the polling results as more objective than face-to-face methods, as "...the amount of people who did this is on a level that we normally will not reach in personal meetings. So it makes it of course more valuable, the objective part."(RP1B). While true statistical representativeness ("1000 people is not representative for [the country]."-RP2A) can never be attained, the amount of polling responses was considered convincing ("For most questions you have between 200 and 300 responses. You can conclude something based on that."-HB2), particularly when these responses can then be combined with other approaches ("You can then place other methods next to it; talk to certain organizations or have conversations with inhabitants."-HB2). 5 stakeholders ( $\mathrm{N}=10$ ) suggested they believed that PPD reached a broader section of citizens compared to conventional participation methods like online platforms ("[Platforms] are only accessible to people like me, who are interested and socially engaged"-MH4) and workshops ("I suspect we also heard the voice of people who do not have the desire to attend the [workshop] with their negativity."-HB1). Stakeholders found that the polling results gained significant value when the demographics of the participants (such as depicted in Figure 5) were revealed via the responses on specific demographic polling questions (e.g. "How often do you visit here?" or "How old are you?").

In contrast, the ability to anonymously vote multiple times hampered stakeholders to find the results fully representative because "...you cannot check if there is one person starting 100 sessions."(RP1A). Stakeholders recognized the possibility to publish intermediate results as feedback to participants, yet felt that this would diminish their trust because it could bias future responses, as participants might want to counter any preliminary outcome ("If trends are published too soon, it can cause a distorted view of the responses due to reactions to that trend."-HB1). Stakeholders trusted the PPD results more than face-to-face interviews as the anonymity of the polling limited social types of bias, in which "...people give responses they assume the person wants to hear."(MH1). The PPD results were also trusted because they corresponded with prior results from other participatory activities, such as when they revealed interest in the concept of 'city forests' "... which also complies actually with all the input we got already before in the participation process"(RP1A).
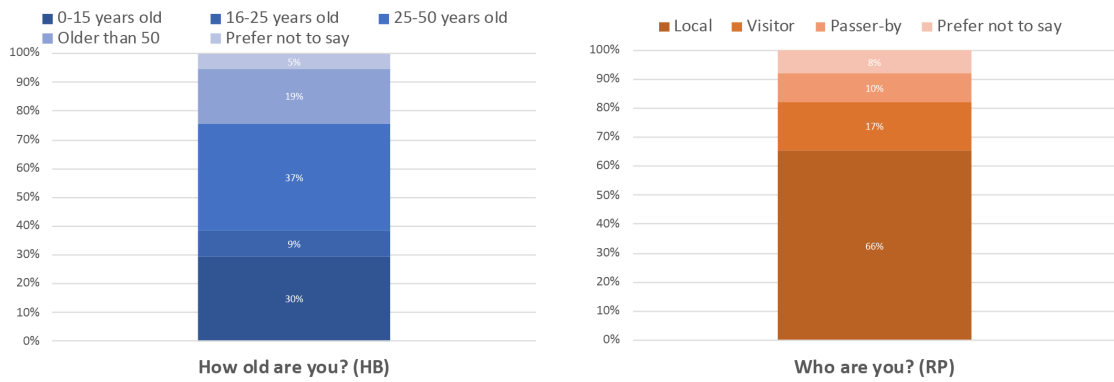

Fig. 5. The given responses on specific demographic polling questions suggest that PPDs successfully reached different age groups (left from HB) yet notably fewer by 16-25 year olds, and were mainly used by locals (right from RP). 
Finally, the results were also considered trustworthy because of our academic affiliation ("I trusted that [the facilitators and MH4] were going to find the responses to the fundamental question we put forth"-MH1).

Challenge 6: Representativeness and Trust. Guaranteeing the representativeness of the resulting insights is challenging, even when the polling results of PPDs are trusted more because they are relatively voluminous, lack implicit social influence, can include self-reported demographic information from participants that are believed to be more diverse, and can be benchmarked with insights that were derived by other participative means. Yet for PPD to effectively work as an opportunistic and meaningful polling medium, an equilibrium needs to be found between encouraging participants to give their opinion because their response carries some weight, and clarifying that no decisions will be made solely based on analyzing the raw results.

\subsection{Follow-Up Phase}

6.4.1 Impact. In $\mathrm{MH}$, the numerical PPD insights were combined with qualitative findings from the workshops to derive concrete design requirements to a governmental funding agency. Moreover, this complementary approach was proposed as a feasible methodology to determine the hyperlocal requirements for future MobiHubs in other municipalities. Consequently, the PPD insights were instrumental in acquiring additional funding to actually implement a Mobility Hub ("[We explained] that we did this poll and were able to get a lot out of that, including that there is indeed some bottom-up support for this."-MH3). Other polling results were distributed internally to act as empirical evidence during policy debates ("I have given [the results] to a number of people already, really as armor, the hard numbers from our inhabitants."-HB1). In two cases, the resulting findings were publicly communicated back to citizens and indirectly used to hold the stakeholder accountable and intended to motivate further actions.

6.4.2 Communicating Findings Back to Citizens. Stakeholders explained the importance of communicating findings back to participants to "...keep citizens involved and show that [they] are absolutely still working on it."(MH3) as a way to maintain trust "...but also to dig deeper and get more insights"(HB1) and "...communicate very widely the actions that will follow out of this."(HB2). However, the insights were only communicated back to citizens in two cases, such as by way of a short journalistic article in a municipal magazine distributed to all inhabitants and a 9 minute slideshow presentation on YouTube (HB), or a 2-page section in a yearly report and a 3 minute YouTube video of interviewed participants (HN) (see Figure 6). HN1 also planned to organize a debate evening around the responses as "... can engage an audience."-HN1.
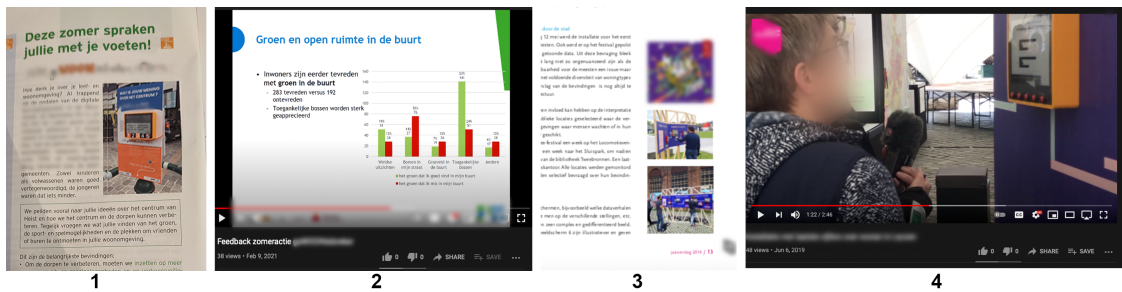

Fig. 6. So far, the main PPD findings were communicated back in a municipal magazine (1, HB), a voice-over slideshow presentation on YouTube and the Facebook account of the stakeholder (2, HB), a yearly report (3, HN) and an interview video on YouTube and the stakeholder's website $(4, \mathrm{HN})$. 
Challenge 7: Feedback to Citizens. Although there is a general consensus about its value, communicating the core PPD results and insights back to participants is challenging because they mainly consists of numerical evidence that is hard to persuasively represent to a lay audience. As such, it seems obvious that the two stakeholders who did so, used very common types of information representation (e.g. slideshow, textual article) through communication channels (e.g. social media) they already mastered. Consequently, it is likely that that not every participant who interacted with the PPDs was reached. Instead, facilitators might aid stakeholders to generate appropriate representations of findings for a lay audience in a timely manner. These communications should preferably also target the original locations of the PPD.

6.4.3 Secondary Stakeholders. Most primary stakeholders involved additional secondary experts to support them. Various municipal experts repeatedly checked the accuracy of the presented housing statistics in HN ("[We made sure] that the data that was communicated was also interpreted correctly"-HN2) and whether the polling questions aligned with the official policies of the city. Additional municipal workers specialized in engaging with marginalized citizens were consulted to review the accessibility of the content ("The people who used to work in [social services]."HB2). Other stakeholders related this expertise to "...support from the 'area-oriented operations' division" (HN2) with expertise in civic participation, yet did not consult them during 'Orchestration'. The communication divisions of the municipal stakeholders were either absent or sparsely involved ("We were not able to discuss how it would all work [with them]."-MH3), as their expertise was considered to relate to promotion rather than the design of the polling questions ("Regarding the formulation of questions, they were less involved"-HB1). Yet stakeholders recognized how their copywriting and media creation skills could have elevated the 'Orchestration' in terms of presenting ideas or illustrating concepts on the PPDs ("We might have used illustration or sketches."-HB2).

Challenge 8: Managing Stakeholders. PPDs require a range of disciplinary skills across the whole process that are not necessarily present in stakeholders nor facilitators, insofar that facilitator should alert stakeholders beforehand of the additional expertise that is expected during each phase. For instance, we believe that PPDs would gain from involving communication experts during 'Orchestration' to augment polling questions, or data managers to provide up-to-date statistical data to contextualize answering options. While the benefit of combining different types of expertise appears self-evident, the active involvement of secondary stakeholders remains challenging to facilitate, manage and align in real-world conditions.

\section{DISCUSSION}

\subsection{PPD Process Model}

Although participants and secondary stakeholders are included in the PPD process model, it is centered around the collaboration between facilitators and primary stakeholders. Because the model only reflects the activities of ourselves as facilitators and the observed and self-reported actions of the primary stakeholders, it is not meant as a comprehensive mapping of all the factors that underlie a PPD process. While prior models have provided actionable insight into the role of context [62], value [46], local and personal relevance [54], spatial location [20] and social interactions [68] in increasing the engagement with public displays in general, we are not aware of attempts to capture the collaborative processes behind their deployments. We thus believe our model has value in informing future PPD and even public display deployments in general, in particular by foregrounding the seldom-reported activities that occur before (i.e. 'Formation' and 'Orchestration') and after (i.e. 'Interpretation' and 'Follow-up') the actual deployment itself. 
We realize that the challenges we discovered from the stakeholder perspective are predicated by our hands-on involvement as facilitators who have years of experience in public display research. Additional challenges will therefore likely emerge in a future where PPDs are deployed autonomously by stakeholders, as they then would need to take care of many practical, technological and data work issues.

If the four cases are critically analyzed through the spectrum of public participation [19], the PPDs never achieved above a consultation level, i.e. where feedback is obtained from citizens. However, when considering the larger civic engagement processes in which the PPDs were only one small part, the PPDs were able to help substantially in 'involving' citizens, because they built upon and informed the discovery of public concerns and aspirations.

We yet believe the model could be potentially further expanded to include activities towards 'collaboration' and 'empowering' citizens in the future. For instance, PPDs could be part of longer-term yet iterative deployments where successive feedback and polling is offered based on previous deployments, or where citizens are actively involved in orchestrating the polling questions, locations or timings, or in transparently processing and analyzing the results.

\subsection{Reflections on the Challenges}

7.2.1 C1: Aligning Expectations. The stakeholders reported varying levels of satisfaction depending on their initial expectations of the PPD's capabilities and their prior experience with quantitative polling methods. Although stakeholders pointed to the added value of PPD, its technological novelty limited their frame of reference insofar that expectations were often misaligned by other polling approaches such as on online platforms that have more interactive features, or more situated methods that provide very circumstantial and qualitative results. As all stakeholders perceived PPD as a medium in its own right, we yet foresee that it could become a complementary rather than a replacement method in the practice of civic engagement.

7.2.2 C2: Designing Content. Although all stakeholders reported some prior experience regarding civic engagement, determining the polling questions required more specialized expertise. We recognized how stakeholders struggled with making questions relevant from the viewpoint of a very specific location, allowing them to reflect previous responses, and presenting them as a fluid narrative that gradually increased in complexity.

Simultaneously, the content was expected to be direct and actionable but not suggesting of any binding commitment; timely and relevant but not too provocative; and accompanied with information that was factually grounded and accessible. This tightly interconnected list of content requirements raises questions in how far content could be determined independently from facilitators with appropriate knowledge in interaction, visual and narrative design.

7.2.3 C3: Timing the Deployment. As most deployments had to be aligned with more encompassing civic engagement activities, there was little room for technical errors. Each new PPD deployment requires ample time for testing, and should be rolled-out gradually instead of being kicked off with a prestigious press event (as we unfortunately had to experience in $\mathrm{HB}$ and $\mathrm{HN}$ ). In retrospect, we even recommend to first deploy a PPD at the stakeholders' own locations, who can then test and report back any concerns first-hand.

7.2.4 C4: Participant Perceptions. While stakeholders valued the perception of PPDs as innocuous devices, they were amazed how few participants directly contacted them to provide feedback. Instead, the very few participants who provided feedback raised obvious yet valid concerns regarding the representativeness and accessibility of the approach via common social media channels. We presume that participants also consider these concerns towards all other common civic engagement methods, who all are vulnerable to these concerns [69]. 
7.2.5 C5: Interpreting Responses. It became very clear that stakeholders required substantial assistance to process and analyze the polling responses from a raw or even visualized dataset. This issue reportedly also occurs when stakeholders need to analyze numerical data from other types of polling systems ("In the end, it was an online platform [...] people are afraid to use, or don't know how to handle the data."-HB2) as well as more qualitative methods [38], of which the analysis is often outsourced to third parties because it is considered costly, time consuming, complicated and tedious.

7.2.6 C6: Trust and representativeness. Stakeholders questioned the representativeness of the PPD results, but not more so than of other methods. For instance, they believed that PPDs overcome the influence of social desirability compared to on-site interviews. However, public display interaction is in itself not devoid of social influences as unclear affordances and the absence of a quick ways to terminate can cause "social awkwardness" [9]. Stakeholders also appreciated receiving our behavioral data from occasional observations and the concrete demographic statistics that we gathered via specific polling questions, i.e. potential methodological improvements that however clash with how citizens prefer to provide feedback fully anonymously [37].

We found that the trust of stakeholders was particularly established by the amount and diversity of unique participants combined with the lack of social influence, which aligns with the perceived representativeness of face-to-face and online civic engagement approaches [38].

7.2.7 C7: Feedback to Citizens. Although most stakeholders identified it as a core value of PPD, none used locative media to communicate the resulting insights back to citizens. By limiting the feedback to other digital and municipal channels, it likely does not reach participants that are more situated and circumstantial to the PPD location and do not access the municipal communication, such as visitors and commuters.

7.2.8 C8: Managing Stakeholders. PPDs require interdisciplinary knowledge, sometimes even across multiple organizations or levels of government (e.g. HB1 and HB2). This means that PPDs should not only be studied as a human-computer interface, but also as a 'product-service system' [60]. Such a service might ideally be a collaborative effort, in which the location-specific expertise of stakeholders is supplemented with visual, interaction and data work experience.

\subsection{Addressing the Challenges}

While the expectations of a PPD system should be best addressed in the initial 'Formation' process, mediating activities should continue throughout the whole deployment. During 'Orchestration', we observed a need for live demonstrations and the pre-visualization of content in visual authoring tools to demonstrate the final visual representation and its interaction latency, but also to optimize the wording or sequencing of responsive questions. The potential to offer different languages or content depending on demographic input shows further promise in establishing PPDs as a more inclusive civic engagement tool.

Although stakeholders also valued the quantitative outcomes, there is a still untapped potential to exploit PPDs as a situational conversation starter similar to $[12,34,64]$, or as a way to elicit qualitative feedback on real-time data measurements like busyness at tourist locations [31] in real-world civic engagement initiatives.

While the feedback loop we facilitated between 'Processing' and 'Analysis' was functional, it was perhaps less conducive to more contextually grounded insights because it creates a barrier between the facilitators and the local knowledge of stakeholders. Other research has shown potential methods to task multidisciplinary teams of policy experts, visualizers and community members to process quantitative data cooperatively in order to effectively enable 
community action [67]. The results of this 'Analysis' ideally are straightforward outcomes that are communicated in easy to share formats with all stakeholders [40].

\subsection{Our Role as Facilitator-Researcher}

Echoing the iterative nature of deployments represented in the proposed model, our own thinking about the system also evolved across the different cases. As we became increasingly aware of the technical, interactive and collaborative challenges and opportunities, we optimized aspects of the PPD system (e.g. responsiveness of the questions) and its deployment (e.g. offering more active guidance in interpreting the data), which in turn improved both the participant and stakeholder experience.

Our role often shifted between researcher, facilitator and paid service provider. This combination of roles caused us to make concessions towards the stakeholders who all had high expectations. We often realized that we were entrusted with their reputation in publicly promoting a functioning system that produces credible polling results. As all these tasks took so much time and effort, part of our research strategy became more opportunistic instead of systematic. Likewise, our research role also limited our willingness to optimize the PPD system in the direction of stakeholders, as we estimated that implementing live data dashboards or better battery life would lead to only minor scientific contributions.

\subsection{Limitations}

As three cases were funded by interviewed stakeholders, their answers might be positively biased towards defending their financial investment, or negatively biased towards alerting us to their grievances as clients. We yet believe that our study carries more ecological validity than typical in-the-wild studies by bridging practice-based and academic knowledge. As all interviews were carried out after the four cases were accomplished, the duration between the deployments and the interviews differs from case to case (from three months to 1.5 years). While some recollections of the earliest stakeholders might be diminished, this post-deployment approach enabled us to focus on the most significant impact that only occurred later or could still be remembered. We also recognize that the PPD system imposes crucial accessibility restrictions, such as to people with visual or, specifically regarding the foot pedals, mobility impairment. This is yet an often overlooked concern for public displays in general, including by our stakeholders.

\section{CONCLUSION}

We presented a retrospective review of four PPD deployments that facilitated civic engagement in real-world context by interviewing 12 civic stakeholder from 10 different organizations, five of which actually financially funded the deployment. The results show that our PPD performed satisfactory and even better than alternative civic engagement methods in several regards, and that stakeholders value its opportunistic and accessible interaction modality to gather location-specific responses. The interviewed stakeholders generally trusted the polling results and believed it aggregated opinions that are difficult to capture otherwise, but also made several suggestions to how the results might become more trustworthy. We synthesized all the underlying deployment activities in a process model, which frames the eight core challenges that withhold PPD to become a more widespread and complementary medium for civic engagement.

\section{ACKNOWLEDGMENTS}

Removed for anonymity. 


\section{REFERENCES}

[1] Anne Adams, Elizabeth Fitzgerald, and Gary Priestnall. 2013. Of Catwalk Technologies and Boundary Creatures. ACM Trans. Comput.-Hum. Interact. 20, 3 (2013), 34 pages. https://doi.org/10.1145/2491500.2491503 Place: New York, NY, USA Publisher: ACM.

[2] Sherry R. Arnstein. 1969. A Ladder Of Citizen Participation. Journal of the American Institute of Planners 35, 4 (1969), $216-224$. https://doi.org/10. 1080/01944366908977225

[3] Mara Balestrini, Sarah Gallacher, and Yvonne Rogers. 2020. Moving HCI Outdoors: Lessons Learned from Conducting Research in the Wild. In HCI Outdoors: Theory, Design, Methods and Applications, D. Scott McCrickard, Michael Jones, and Timothy L. Stelter (Eds.). Springer International Publishing, 83-98. https://doi.org/10.1007/978-3-030-45289-6 4

[4] Mara Balestrini, Yvonne Rogers, and Paul Marshall. 2015. Civically Engaged HCI: Tensions between Novelty and Social Impact. In Proceedings of the 2015 British HCI Conference (Lincoln, Lincolnshire, United Kingdom) (British HCI '15). ACM, 35-36. https://doi.org/10.1145/2783446.2783590

[5] Moritz Behrens, Nina Valkanova, Ava Fatah gen. Schieck, and Duncan P. Brumby. 2014. Smart Citizen Sentiment Dashboard: A Case Study Into Media Architectural Interfaces. In Proceedings of PerDis '14 (New York, NY, USA). ACM, 19:19-19:24. https://doi.org/10.1145/2611009.2611036

[6] Thomas C. Beierle. 1999. Using Social Goals To Evaluate Public Participation In Environmental Decisions. Review of Policy Research 16, 3 (1999), 75-103. https://doi.org/10.1111/j.1541-1338.1999.tb00879.x

[7] Mark Bilandzic and John Venable. 2011. Towards participatory action design research: adapting action research and design science research methods for urban informatics. Journal of Community Informatics 7, 3 (2011), 1-15. https://doi.org/10.15353/joci.v7i3.2592

[8] Hermann-Josef Blanke and Stelio Mangiameli. 2013. Article 11: Participatory Democracy. In The Treaty on European Union (TEU): A Commentary. Springer Berlin Heidelberg, 449-465. https://doi.org/10.1007/978-3-642-31706-4_12

[9] Harry Brignull and Yvonne Rogers. 2003. Enticing people to interact with large public displays in public spaces. In INTERACT, Vol. 3. IFIP, 17-24.

[10] Deborah Carr and Kathleen Halvorsen. 2001. An Evaluation of Three Democratic, Community-Based Approaches to Citizen Participation: Surveys, Conversations With Community Groups, and Community Dinners. Society and Natural Resources 14 (2001), 107-126. https://doi.org/10.1080/ 089419201300000526

[11] Alan Chamberlain, Andy Crabtree, Tom Rodden, Matt Jones, and Yvonne Rogers. 2012. Research in the Wild: Understanding 'in the Wild' Approaches to Design and Development. In Proceedings of the Designing Interactive Systems Conference (Newcastle Upon Tyne, United Kingdom) (DIS '12). ACM, 795-796. https://doi.org/10.1145/2317956.2318078

[12] Sandy Claes, Jorgos Coenen, and Andrew Vande Moere. 2018. Conveying a Civic Issue Through Data via Spatially Distributed Public Visualization and Polling Displays. In Proceedings of NordiCHI '18 (New York, NY, USA). ACM, 597-608. https://doi.org/10.1145/3240167.3240206

[13] Antoine Clarinval, Anthony Simonofski, Benoit Vanderose, and Bruno Dumas. 2020. Public displays and citizen participation: a systematic literature review and research agenda. Transforming Government: People, Process and Policy ahead-of-print (2020), 1-34. https://doi.org/10.1108/TG-12-20190127

[14] Jorgos Coenen, Sandy Claes, and Andrew Vande Moere. 2017. The concurrent use of touch and mid-air gestures or floor mat interaction on a public display. In Proceedings of the 6th ACM International Symposium on Pervasive Displays - PerDis '17 (Lugano, Switzerland). ACM Press, 1-9. https://doi.org/10.1145/3078810.3078819

[15] Jorgos Coenen, Eslam Nofal, and Andrew Vande Moere. 2019. How the Arrangement of Content and Location Impact the Use of Multiple Distributed Public Displays. In Proceedings of DIS '19 (New York, NY, USA). ACM, 1415-1426. https://doi.org/10.1145/3322276.3322294

[16] Guiying Du, Auriol Degbelo, and Christian Kray. 2017. Public Displays for Public Participation in Urban Settings: A Survey. In Proceedings of the 6th ACM International Symposium on Pervasive Displays (New York, NY, USA) (PerDis '17). ACM, 1-9. https://doi.org/10.1145/3078810.3078825

[17] Titiana-Petra Ertiö. 2015. Participatory Apps for Urban Planning-Space for Improvement. Planning Practice \& Research 30, 3 (2015), $303-321$. https://doi.org/10.1080/02697459.2015.1052942

[18] Thore Fechner, Dominik Schlarmann, and Christian Kray. 2016. Facilitating Citizen Engagement in Situ: Assessing the Impact of pro-Active Geofenced Notifications. In Proceedings of the 18th International Conference on Human-Computer Interaction with Mobile Devices and Services (New York, NY, USA) (MobileHCI '16). ACM, 353-364. https://doi.org/10.1145/2935334.2935379

[19] IAP2 International Federation. 2018. IAP2 Spectrum of Public Participation. https://www.iap2.org/page/pillars Accessed: 2020-02-20.

[20] Patrick Tobias Fischer and Eva Hornecker. 2012. Urban HCI: Spatial Aspects in the Design of Shared Encounters for Media Facades. In Proceedings of CHI '12 (New York, NY, USA). ACM, 307-316. https://doi.org/10.1145/2207676.2207719 event-place: Austin, Texas, USA.

[21] Joel Fredericks and Marcus Foth. 2013. Augmenting public participation: enhancing planning outcomes through the use of social media and web 2.0. Australian Planner 50, 3 (2013), 244-256. https://doi.org/10.1080/07293682.2012.748083 arXiv:https://doi.org/10.1080/07293682.2012.748083

[22] Connie Golsteijn, Sarah Gallacher, Lisa Koeman, Lorna Wall, Sami Andberg, Yvonne Rogers, and Licia Capra. 2015. VoxBox: A Tangible Machine That Gathers Opinions from the Public at Events. In Proceedings of the Ninth International Conference on Tangible, Embedded, and Embodied Interaction (New York, NY, USA) (TEI '15). ACM, 201-208. https://doi.org/10.1145/2677199.2680588

[23] Jorge Goncalves, Simo Hosio, Yong Liu, and Vassilis Kostakos. 2014. Eliciting situated feedback: A comparison of paper, web forms and public displays. Displays 35, 1 (2014), 27 - 37. https://doi.org/10.1016/j.displa.2013.12.002

[24] Jorge Goncalves, Simo Hosio, Jakob Rogstadius, Evangelos Karapanos, and Vassilis Kostakos. 2015. Motivating participation and improving quality of contribution in ubiquitous crowdsourcing. Computer Networks 90 (2015), 34 - 48. https://doi.org/10.1016/j.comnet.2015.07.002 
[25] Ahmet Gün, Yüksel Demir, and Burak Pak. 2020. Urban design empowerment through ICT-based platforms in Europe. International fournal of Urban Sciences 24, 2 (2020), 189-215. https://doi.org/10.1080/12265934.2019.1604250

[26] Mike Harding, Bran Knowles, Nigel Davies, and Mark Rouncefield. 2015. HCI, Civic Engagement \& Trust. In Proceedings of the 33rd Annual ACM Conference on Human Factors in Computing Systems (New York, NY, USA). ACM, 2833-2842. https://doi.org/10.1145/2702123.2702255

[27] Gillian R. Hayes. 2011. The Relationship of Action Research to Human-computer Interaction. ACM Trans. Comput.-Hum. Interact. 18, 3 (2011), 15:1-15:20. https://doi.org/10.1145/1993060.1993065

[28] Luke Hespanhol and Martin Tomitsch. 2019. Power to the People: Hacking the City with Plug-In Interfaces for Community Engagement. In The Hackable City: Digital Media and Collaborative City-Making in the Network Society, Michiel de Lange and Martijn de Waal (Eds.). Springer Singapore, 25-50. https://doi.org/10.1007/978-981-13-2694-3_2

[29] Luke Hespanhol, Martin Tomitsch, Ian McArthur, Joel Fredericks, Ronald Schroeter, and Marcus Foth. 2015. Vote as You Go: Blending Interfaces for Community Engagement into the Urban Space. In Proceedings of the 7th International Conference on Communities and Technologies (New York, NY, USA) (C\&T '15). ACM, 29-37. https://doi.org/10.1145/2768545.2768553

[30] Simo Hosio, Jorge Goncalves, Vassilis Kostakos, and Jukka Riekki. 2014. Exploring Civic Engagement on Public Displays. In User-Centric Technology Design for Nonprofit and Civic Engagements, Saqib Saeed (Ed.). Springer International Publishing, 91-111. https://doi.org/10.1007/978-3-319-05963-1_7

[31] Steven Houben, Ben Bengler, Daniel Gavrilov, Sarah Gallacher, Valentina Nisi, Nuno Jardim Nunes, Licia Capra, and Yvonne Rogers. 2019. Roam-IO: Engaging with People Tracking Data Through an Interactive Physical Data Installation. In Proceedings of the 2019 on Designing Interactive Systems Conference (New York, NY, USA) (DIS '19). ACM, 1157-1169. https://doi.org/10.1145/3322276.3322303

[32] Steven Houben and Christian Weichel. 2013. Overcoming Interaction Blindness Through Curiosity Objects. In CHI '13 Extended Abstracts on Human Factors in Computing Systems (New York, NY, USA) (CHI EA '13). ACM, 1539-1544. https://doi.org/10.1145/2468356.2468631

[33] Peter A. Johnson, Pamela J. Robinson, and Simone Philpot. 2020. Type, tweet, tap, and pass: How smart city technology is creating a transactional citizen. Government Information Quarterly 37, 1 (2020), 10. https://doi.org/10.1016/j.giq.2019.101414

[34] Lisa Koeman, Vaiva Kalnikaité, and Yvonne Rogers. 2015. "Everyone Is Talking About It!": A Distributed Approach to Urban Voting Technology and Visualisations. In Proceedings of CHI '15 (New York, NY, USA). ACM, 3127-3136. https://doi.org/10.1145/2702123.2702263

[35] Can Liu, Ben Bengler, Danilo Di Cuia, Katie Seaborn, Giovanna Nunes Vilaza, Sarah Gallacher, Licia Capra, and Yvonne Rogers. 2018. Pinsight: A Novel Way of Creating and Sharing Digital Content Through 'Things' in the Wild. In Proceedings of the 2018 Designing Interactive Systems Conference (New York, NY, USA) (DIS '18). ACM, 1169-1181. https://doi.org/10.1145/3196709.3196782

[36] Thomas Mahatody, Mouldi Sagar, and Christophe Kolski. 2010. State of the art on the cognitive walkthrough method, its variants and evolutions. Intl. Journal of Human-Computer Interaction 26, 8 (2010), 741-785.

[37] Narges Mahyar, Michael R. James, Michelle M. Ng, Reginald A. Wu, and Steven P. Dow. 2018. CommunityCrit: Inviting the Public to Improve and Evaluate Urban Design Ideas Through Micro-Activities. In Proceedings of the 2018 CHI Conference on Human Factors in Computing Systems (New York, NY, USA) (CHI '18). ACM, 195:1-195:14. https://doi.org/10.1145/3173574.3173769

[38] Narges Mahyar, Diana V. Nguyen, Maggie Chan, Jiayi Zheng, and Steven P. Dow. 2019. The Civic Data Deluge: Understanding the Challenges of Analyzing Large-Scale Community Input. In Proceedings of the 2019 on Designing Interactive Systems Conference (San Diego, CA, USA) (DIS '19). ACM, 1171-1181. https://doi.org/10.1145/3322276.3322354

[39] Albert Meijer. 2015. E-governance innovation: Barriers and strategies. Government Information Quarterly 32, 2 (2015), 198 - $206 . \quad$ https: //doi.org/10.1016/j.giq.2015.01.001

[40] Vicki Moulder, Lorna R. Boschman, Ron Wakkary, William Odom, and Stacey Kuznetsov. 2014. HCI Interventions with Nonprofit Organizations: Tactics for Effective Collaboration. In CHI '14 Extended Abstracts on Human Factors in Computing Systems (Toronto, Ontario, Canada) (CHI EA '14). ACM, 877-880. https://doi.org/10.1145/2559206.2559971

[41] Ville Mäkelä, Sumita Sharma, Jaakko Hakulinen, Tomi Heimonen, and Markku Turunen. 2017. Challenges in Public Display Deployments: A Taxonomy of External Factors. In Proceedings of CHI '17 (New York, NY, USA). ACM, 3426-3475. https://doi.org/10.1145/3025453.3025798

[42] Jörg Müller, Dennis Wilmsmann, Juliane Exeler, Markus Buzeck, Albrecht Schmidt, Tim Jay, and Antonio Krüger. 2009. Display Blindness: The Effect of Expectations on Attention towards Digital Signage. In Pervasive Computing (Berlin, Heidelberg). Springer Berlin Heidelberg, 1-8. https://doi.org/10.1007/978-3-642-01516-8

[43] J. Nakazawa and H. Tokuda. 2007. Phygital Map: Accessing Digital Multimedia from Physical Map. In 21st International Conference on Advanced Information Networking and Applications Workshops (AINAW'07), Vol. 2. IEEE, 368-373. https://doi.org/10.1109/AINAW.2007.288

[44] Timo Ojala, Vassilis Kostakos, Hannu Kukka, Tommi Heikkinen, Tomas Linden, Marko Jurmu, Simo Hosio, Fabio Kruger, and Daniele Zanni. $2012-05$. Multipurpose Interactive Public Displays in the Wild: Three Years Later. Computer 45, 5 (2012-05), 42-49. https://doi.org/10.1109/MC.2012.115 Place: Washington, DC, USA Publisher: IEEE Computer Society Press.

[45] Callum Parker, Marius Hoggenmueller, and Martin Tomitsch. 2018. Design Strategies for Overcoming Failures on Public Interactive Displays. In Proceedings of the 7th ACM International Symposium on Pervasive Displays (New York, NY, USA) (PerDis '18). ACM, 2:1-2:7. https:/doi.org/10.1145/ 3205873.3205889

[46] Callum Parker, Martin Tomitsch, Nigel Davies, Nina Valkanova, and Judy Kay. 2020. Foundations for Designing Public Interactive Displays That Provide Value to Users. In Proceedings of CHI '20 (New York, NY, USA). ACM, 1-12. https://doi.org/10.1145/3313831.3376532

[47] Callum Parker, Martin Tomitsch, and Judy Kay. 2018. Does the Public Still Look at Public Displays?: A Field Observation of Public Displays in the Wild. Proc. ACM Interact. Mob. Wearable Ubiquitous Technol. 2, 2 (2018), 73:1-73:24. https://doi.org/10.1145/3214276 
[48] Phil Parvin. 2018. Democracy Without Participation: A New Politics for a Disengaged Era. Res Publica 24, 1 (2018), 31-52. https://doi.org/10.1007/ s11158-017-9382-1

[49] J. Ponterotto. 2006. Brief Note on the Origins, Evolution, and Meaning of the Qualitative Research Concept "Thick Description". The Qualitative Report 11 (2006), 538-549.

[50] PJ Robinson and M DeRuyter. 2016. I 'like'you, you make my heart twitter, but... reflections for urban planners from an early assessment of social media deployment by Canadian local governments. Oxford University Press Don Mills, ON. 260-268 pages.

[51] Yvonne Rogers. 2011. Interaction Design Gone Wild: Striving for Wild Theory. Interactions 18, 4 (2011), 58-62. https://doi.org/10.1145/1978822. 1978834

[52] Lynn M Sanders. 1997. Against deliberation. Political theory 25, 3 (1997), 347-376.

[53] Gianluca Schiavo, Marco Milano, Jorge Saldivar, Tooba Nasir, Massimo Zancanaro, and Gregorio Convertino. 2013. Agora2.0: Enhancing Civic Participation through a Public Display. In Proceedings of the 6th International Conference on Communities and Technologies (New York, NY, USA) (C\&T'13). ACM, 46-54. https://doi.org/10.1145/2482991.2483005

[54] Ronald Schroeter, Marcus Foth, and Christine Satchell. 2012. People, Content, Location: Sweet Spotting Urban Screens for Situated Engagement. In Proceedings of DIS '12 (New York, NY, USA). ACM, 146-155. https://doi.org/10.1145/2317956.2317980

[55] Carolin Schröder. 2015. Through Space and Time: Using mobile apps for urban participation. In Proceedings of CeDEM15: conference for e-democracy and open government. Technische Universität Berlin, 134-142.

[56] Aidan Slingsby, Jason Dykes, Jo Wood, and Robert Radburn. 2014. Designing an exploratory visual interface to the results of citizen surveys. International fournal of Geographical Information Science 28, 10 (2014), 2090-2125. https://doi.org/10.1080/13658816.2014.920845

[57] Fabius Steinberger, Marcus Foth, and Florian Alt. 2014. Vote With Your Feet: Local Community Polling on Urban Screens. In Proceedings of PerDis '14 (New York, NY, USA). ACM, 44:44-44:49. https://doi.org/10.1145/2611009.2611015

[58] Nick Taylor, Keith Cheverst, Peter Wright, and Patrick Olivier. 2013. Leaving the Wild: Lessons from Community Technology Handovers. ACM, New York, NY, USA, 1549-1558. https://doi.org/10.1145/2470654.2466206

[59] Nick Taylor, Justin Marshall, Alicia Blum-Ross, John Mills, Jon Rogers, Paul Egglestone, David M. Frohlich, Peter Wright, and Patrick Olivier. 2012 Viewpoint: Empowering Communities with Situated Voting Devices. In Proceedings of the SIGCHI Conference on Human Factors in Computing Systems (New York, NY, USA) (CHI '12). ACM, 1361-1370. https://doi.org/10.1145/2207676.2208594

[60] Ana Valencia, Ruth Mugge, Jan Schoormans, and Hendrik Schifferstein. 2015. The design of smart product-service systems (PSSs): An exploration of design characteristics. International fournal of Design 9, 1 (2015), 13-28.

[61] Nina Valkanova, Robert Walter, Andrew Vande Moere, and Jörg Müller. 2014. MyPosition: Sparking Civic Discourse by a Public Interactive Poll Visualization. In Proceedings of the 17th ACM Conference on Computer Supported Cooperative Work and Social Computing (Baltimore, Maryland, USA) (CSCW '14). ACM, 1323-1332. https://doi.org/10.1145/2531602.2531639

[62] Andrew Vande Moere and Niels Wouters. 2012. The Role of Context in Media Architecture. In Proceedings of the 2012 International Symposium on Pervasive Displays (New York, NY, USA) (PerDis '12). ACM, 12:1-12:6. https://doi.org/10.1145/2307798.2307810

[63] Vasilis Vlachokyriakos, Rob Comber, Karim Ladha, Nick Taylor, Paul Dunphy, Patrick McCorry, and Patrick Olivier. 2014. PosterVote: Expanding the Action Repertoire for Local Political Activism. In Proceedings of the 2014 Conference on Designing Interactive Systems (New York, NY, USA) (DIS '14). ACM, 795-804. https://doi.org/10.1145/2598510.2598523

[64] Jagoda Walny, Sarah Storteboom, Richard Pusch, Steven Munsu Hwang, Søren Knudsen, Sheelagh Carpendale, and Wesley J. Willett. 2020. PixelClipper: Supporting Public Engagement and Conversation About Visualizations. PRISM. https://doi.org/10.11575/PRISM/10182

[65] C. Webster and Charles Leleux. 2018. Smart governance: Opportunities for technologically-mediated citizen co-production. Information Polity 23 (2018), 1-16. https://doi.org/10.3233/IP-170065

[66] William Foote Whyte, Davydd J Greenwood, and Peter Lazes. 1991. Participatory action research: Through practice to science in social research. Participatory action research 32, 5 (1991), 19-55.

[67] Sarah Williams. 2020. Data Action: Using Data for Public Good. MIT Press.

[68] Niels Wouters, John Downs, Mitchell Harrop, Travis Cox, Eduardo Oliveira, Sarah Webber, Frank Vetere, and Andrew Vande Moere. 2016. Uncovering the Honeypot Effect: How Audiences Engage with Public Interactive Systems. In Proceedings of DIS '16 (New York, NY, USA). ACM, 5-16. https://doi.org/10.1145/2901790.2901796

[69] Kaifeng Yang and Sanjay K. Pandey. 2011. Further Dissecting the Black Box of Citizen Participation: When Does Citizen Involvement Lead to Good Outcomes? Public Administration Review 71, 6 (2011), 880-892. https://doi.org/10.1111/j.1540-6210.2011.02417.x 